\title{
Prototype Clinometer Digital sebagai Alat Kalibrasi Sudut Precision Approach Path Indicator
}

\author{
Suhanto ${ }^{1}$ \\ ${ }^{1)}$ Politeknik Penerbangan Surabaya \\ J1. Jemur Andayani I, No. 73 Surabaya 60236 \\ Email : nadiafather@gmail.com
}

\begin{abstract}
ABSTRAK
Clinometer adalah peralatan yang digunakan untuk mengukur sudut kemiringan secara akurat yang dapat diatur dalam menit dan detik. Clinometer digunakan untuk seting sudut pada Precision Approach Path Indicator (PAPI), sudut elevasi yang ditunjukkan melalui pancaran cahaya yang dihasilkan oleh PAPI. Prototype Clinometer Digital dibuat dengan tampilan digital berupa seven segmen, untuk mendeteksi sudut kemiringan digunakan sensor accelometer yang menjadi masukan mikrokontroler kemudian ditampilkan melalui tampilan seven segmen. Hasil pegujian prototype beroperasi dengan baik, tingkat kesalahan pembacaan clinometer digital ini masih dalam toleransi maksimal yaitu 0,07 derajat.
\end{abstract}

Kata Kunci: Clinometer, Precision Approach Path Indicator (PAPI), Prototype Clinometer Digital, seven segmen, accelometer, mikrokontroler

\section{PENDAHULUAN}

Precision Approach Path Indicator (PAPI) merupakan salah satu alat pendaratan visual yang berfungsi memandu pesawat udara yang akan mendarat dengan memberikan sudut pendaratan yang tepat kepada pesawat udara tersebut. Untuk landas pacu yang dilengkapi Instrumen Landing System (ILS) maka besarnya sudut pendaratan PAPI harus sama dengan sudut pendaratan yang diberikan oleh Glide Slope ILS. Untuk menjamin akurasi sudut peralatan PAPI maka perlu dilakukan kalibrasi penerbangan yang dilakukan setiap enam bulan untuk PAPI dengan ILS dan 24 bulan jika PAPI tanpa ILS. Untuk kalibrasi peralatan PAPI digunakan clinometer untuk seting sudut, clinometer yang digunakan pada umumnya adalah sistem analog. Dalam penelitian ini clinometer dibuat dengan display digital yang digunakan untuk memudahkan pembacaan pengguna pada saat melakukan kalibrasi sudut PAPI. 


\section{KONSEP RANCANGAN}

Dalam pembuatan prototype clinometers digital ini secara garis besar dijelaskan pada blok diagram dibawah ini :

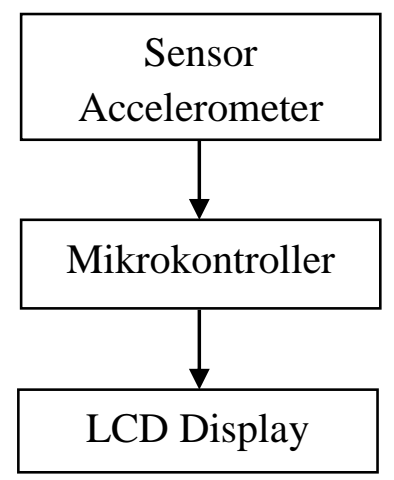

Gambar 1. Blok Diagram Prototype Clinometer

\section{Sensor Accelerometer}

Untuk perancangan prototype clinometer digital diperlukan sensor yang berfungsi untuk mendeteksi kemiringan sudut yang ditunjukkan oleh PAPI. Sensor tersebut adalah sensor accelerometer MMA7361LC. Sensor accelerometer MMA7361LC dapat mengukur tingkat kemiringan sudut PAPI dengan membandingkan percepatan pada posisi PAPI dengan posisi vertikal yang dapat disebut dengan sinus. Sensor accelerometer MMA7361LC memiliki tingkat sensitivitas $\pm 3 \mathrm{~g}$ dan membutuhkan tegangan $3,3 \mathrm{~V}$ sebagai power supply. Pada Gambar2 dan Gambar 3 menunjukkan port yang akan dihubungkan ke dalam mikrokontroler.

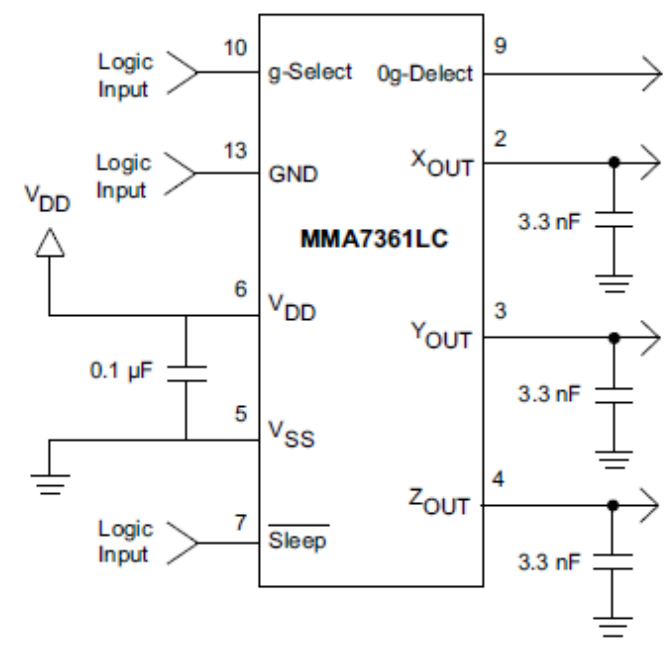

Gambar 2. Accelerometer MMA7361LC 


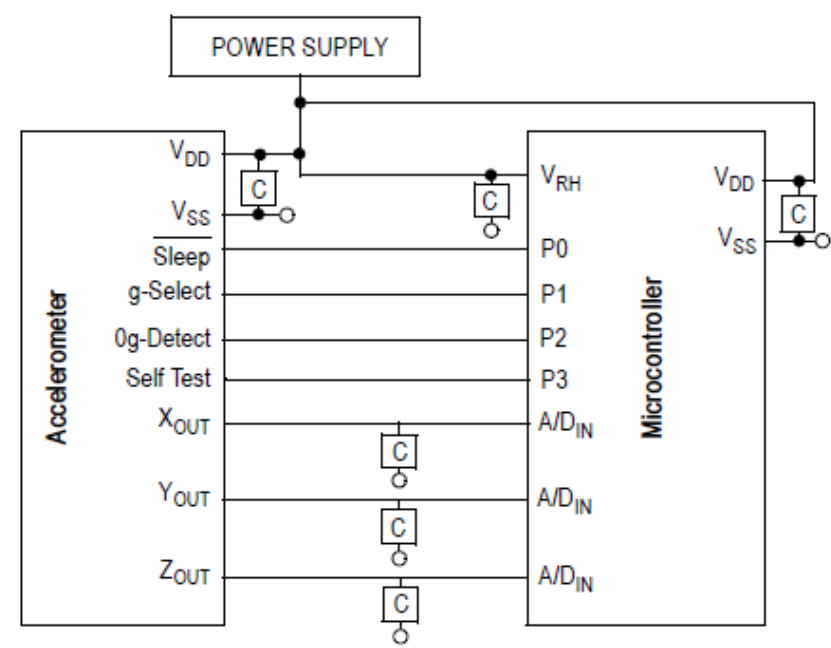

Gambar 3. Port accelerometer MMA7361LC

\section{Mikrokontroler dan LCD Display}

Rangkaian ini terdiri dari 4 kapasitor, 1 IC Mikrokontroller Atmega 8535, 1 buah sensor Accelerometer MMA7361LC.Dari rangkaian tersebut yang berpengaruh terhadap kecepatan proses menjalankan adalah crystal ditunjukkan pada gambar dibawah ini :

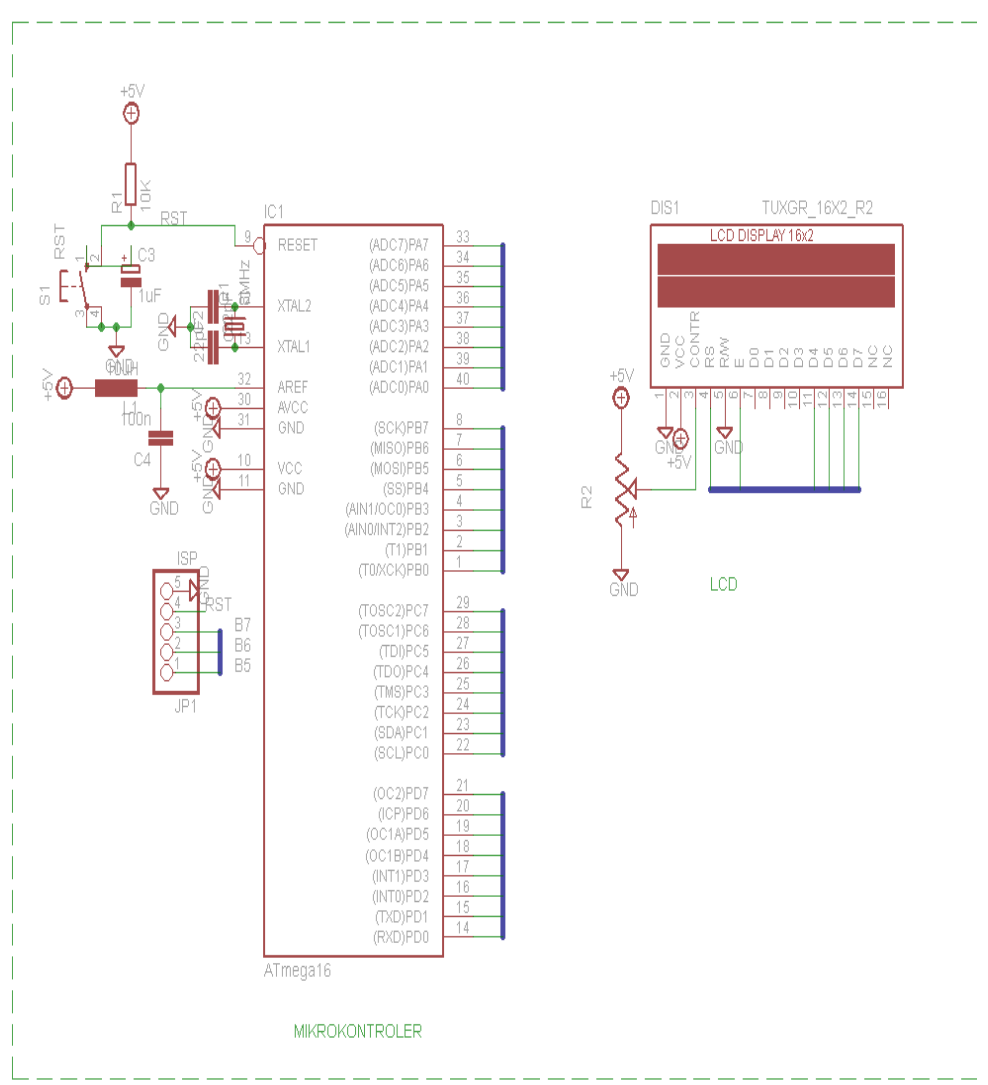

Gambar 4. Rangkaian Mikrokontroller 
Pada port A menghubungkan mikrokontroller dengan sensor accelerometer MM7361LC. Sensor accelerometer disini difungsikan sebagai sensor yang mendeteksi kemiringan sudut pada PAPI. Hasil pengukuran sudut elevasi PAPI dalam rancangan prototype ini, akan ditampilkan dalam bentuk tampilan seven segment $2 \mathrm{X} 4$. Hal ini dimaksudkan untuk lebih memudahkan dalam pembacaan hasil pengukuran dan meminimalisir kesalahan pembacaan. Port $\mathrm{C}$ yang digunakan untuk menghubungkan mikrokontroller dengan seven segmen.

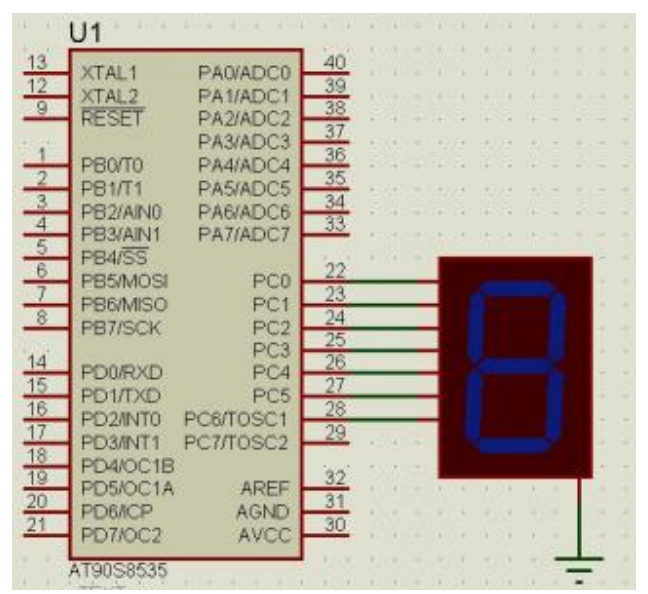

Gambar 5. Rangkaian Seven segment

\section{Komponen Seting Sudut Secara Analog}

Selain perancangan secara digital, clinometer ini juga dilengkapi dengan analog. Ini dimaksudkan agar prototype clinometer tetap bisa digunakan meskipun ada kerusakan pada rancangan digital dan juga dapat dijadikan referensi hasil seting PAPI secara digital. Secara umum komponen yang digunakan untuk merancang prototype clinometer secara analog meliputi :

\section{Waterpas}

Untuk perancangan prototype clinometer secara manual diperlukan waterpass untuk menentukan kerataan box PAPI. Penulis menggunakan 2 buah waterpass yang masingmasing diletakkan pada 2 bidang untuk mengukur kerataan seluruh bidang terhadap sudut elevasi. Ini dimaksudkan supaya clinometer tetap terjaga kerataanya saat diseting. Pada gambar dibawah ini menunjukkan air raksa yang terdapat di dalam waterpass sebagai indikator kemiringan suatu benda.

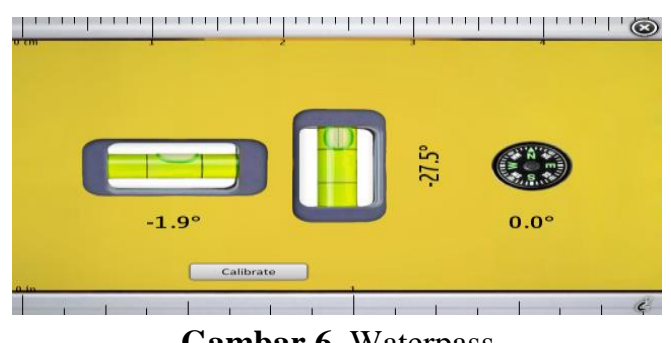

Gambar 6. Waterpass 
Pada saat seting sudut PAPI, ketinggian kaki PAPI akan diubah untuk mencapai sudut elevasi yang diinginkan. Waterpass melalui air raksa menunjukkan keadaan bidang terhadap kemiringan. Bila air raksa tersebut berada tepat ditengah-tengah garis yang ditunjukkan maka bidang tersebut rata terhadap permukaan laut.

\section{Busur Derajat}

Busur derajat digunakan sebagai alat ukur analog untuk menghitung derajat elevasi. Pada penelitian menggunakan 1 buah busur yang dipasang dibelakang clinometer. Busur tersebut menggunakan satuan derajat. $1^{\circ}$ (derajat) sama dengan $60^{\circ}$ (menit).

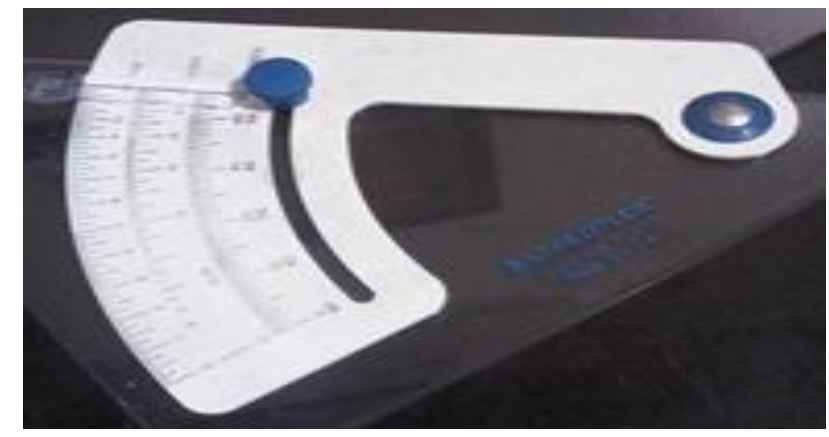

Gambar 7. Busur derajat

\section{Prototype Clinometer Secara Keseluruhan}

Pada gambar diatas menunjukkan bagian-bagian prototype clinometer. Clinometer tersebut dilengkapi dengan analog dan digital. Analog terdiri dari waterpas dan busur derajat sedangkan digital terdiri dari sensor accelerometer, mikrokontroller dan seven segment. Bahan yang digunakan untuk membuat rangka clinometer tersebut adalah alumunium karena bahan tersebut ringan, mudah di dapat dan harganya murah. Rancangan prototype clinometer digital secara keseluruhan adalah sebagai berikut :

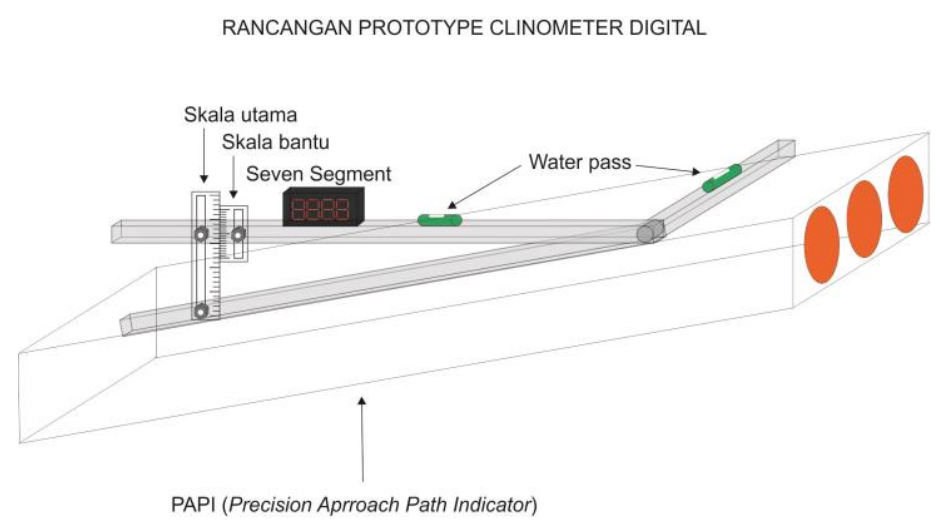

Gambar 8. Prototype Clinometer Digital

\section{Pemrograman Sensor Accelerometer}

Untuk mengisi program dari sensor ke mikrokontroller penulis menggunakan Codevision AVR dengan bahasa C. Listing program sensor accelerometer ke mikrokontroller sebagai berikut : 


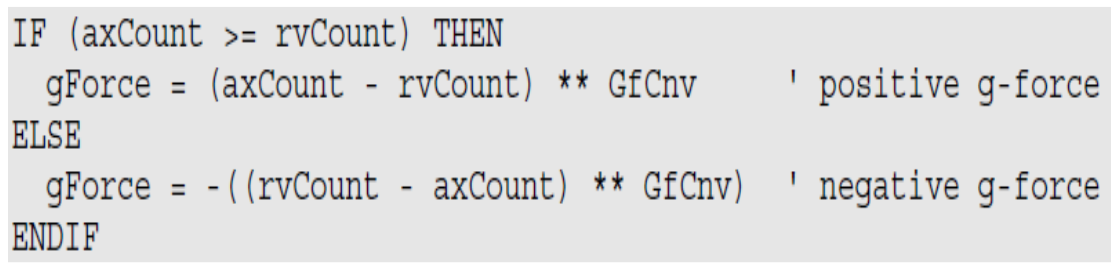

Pada gambar di atas dijelaskan perintah gForce merupakan perintah hasil dari sensor accelerometer. AxCount merupakan perintah yang menandakan bahwa keluaran sensor tersebut adalah data positif, sedangkan rvCount mrnandakan keluaran sensor berupa data negatif. Jika keluaran berupa data positif maka akan diproses oleh mikrokontroller tetapi bila keluarannya berupa data negatif maka data tersebut tidak akan diproses karena data tersebut dianggap error. Ini tunjukkan pada kata ELSE yang tertulis di listing program diatas.

Dalam aplikasi analog, sirkuit pengkondisi sinyal mempengaruhi tingkat pengukuran kemiringan sudut yang diambil sensor accelerometer. Rangkaian filter yang terdapat di dalam sensor tersebut dirancang untuk meminimalkan terjadinya kesalahan dalam pengukuran sudut kemiringan.

\section{Pemrograman Mikrokontroller dan Sevent Segment}

Pemrograman mikrokontroller ke seven segment digunakan Codevision AVR dengan bahasa C. Config adalah perintah yang digunakan untuk menyambungkan port seven segment ke mikrokontroller.

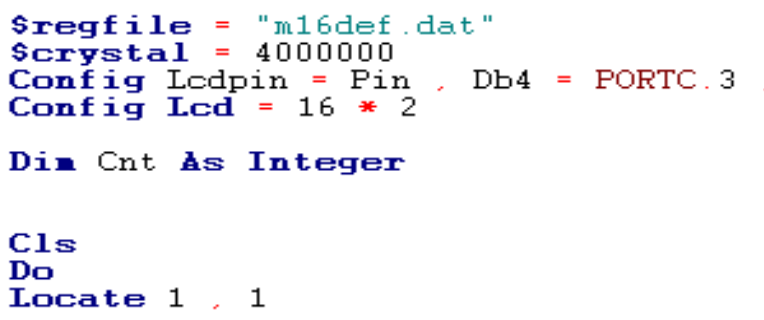

\section{PEMBAHASAN}

\section{Pengujian Sensor Accelerometer}

Sensor accelerometer yang digunakan diletakkan diagonal di dalam box, menjadi satu dengan seven segmen dan mikrokontroller. Hal ini dimaksudkan untuk menambah sensitivitas pada kerja sensor accelerometer. Berikut adalah hasil pengukuran dengan menggunakan referensi analog (busur derajat) dan digital dengan posisi peletakan sensor Accelerometer secara vertikal dan diagonal :

Tabel 1. Hasil pengukuran skala derajat

\begin{tabular}{|c|c|c|c|}
\hline \multirow{2}{*}{ No. } & \multirow{2}{*}{ Analog } & \multicolumn{2}{|c|}{ Sensor Accelerometer } \\
\cline { 3 - 4 } & & Vertikal & Horisontal \\
\hline 1. & $1^{\circ}$ & $1,53^{\circ}$ & $1,05^{\circ}$ \\
\hline 2. & $2^{\circ}$ & $2,30^{\circ}$ & $2,07^{\circ}$ \\
\hline 3. & $3^{\circ}$ & $3,42^{\circ}$ & $3,04^{\circ}$ \\
\hline 4. & $4^{\circ}$ & $4,14^{\circ}$ & $4,04^{\circ}$ \\
\hline
\end{tabular}


Pada tabel menunjukkan bahwa sensor accelerometer akan lebih kecil tingkat kesalahannya jika di letakkan secara horisontal dibandingkan peletakan secara vertikal. Hal tersebut terjadi karena bila sensor accelerometer diletakkan secara horisontal maka sensor tersebut akan lebih sensitif mengukur sumbu x dan y dan sumbu z tidak terlalu berpengaruh. Hasil dari pengukuran menggunakan sensor accelerometer dengan pengukuran secara analog (busur derajat) hasilnya akan berbeda karena sensor accelerometer mengukur 3 sumbu yaitu $\mathrm{x}$, y dan $\mathrm{z}$ sedangkanmengukur secara analog hanya mengukur 2 sumbu yaitu $\mathrm{x}$ dan y saja. Sensor accelerometer cenderung berubah-ubah karena di pengaruhi oleh sumbu $\mathrm{z}$, hal tersebut dikarenakan perputaran bumi pada sumbunya.

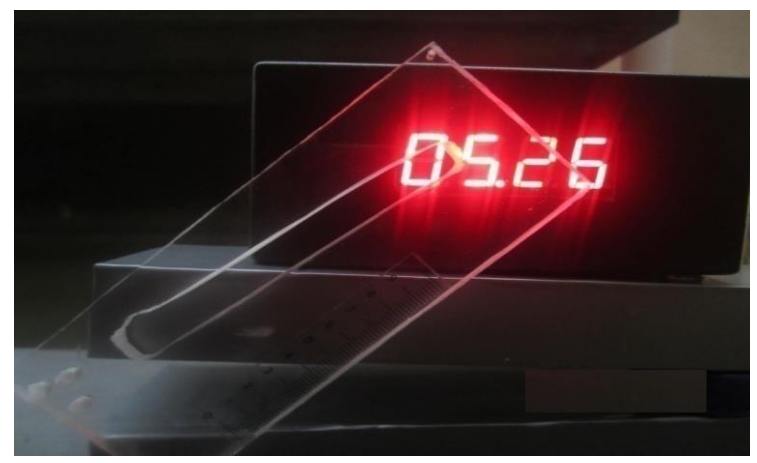

Gambar 9. Pengujian sensor dengan referensi manual clinometer

\section{Pengujian Mikrokontroller}

Power suplai mikrokontroller berupa baterai 9 volt DC dihubungkan ke VDD AT mega 8535 dan sensor accelerometer. Port A pada mikrokontroller dihubungkan ke seven segment dan port B dihubungkan ke port sensor accelerometer.

Pada board mikrokontroller dilengkapi 1 kapasitor $50 \mathrm{~V} 1 \mu \mathrm{F}, 1$ kapasitor $470 \mu \mathrm{F}$ dan 1 kapasitor $16 \mathrm{~V} 470 \mu \mathrm{F}$. Pada kapasitor juga dilengkapi dengan IC LM 7805CV, diode dan 2 buah resistor dengan kapasitas $100.000 \mathrm{ohm}$.

Tabel 2. Port mikrokontroller

\begin{tabular}{|c|c|c|}
\hline No & Port Mikrokontroller & Terhubung \\
\hline 1. & Port A & Seven Segment \\
\hline 2. & Port B & Sensor accelerometer \\
\hline 3. & Vdd & Power supply \\
\hline
\end{tabular}

Pada mikrokontroller tegangan output power supply dan input mikrokontroller terdapat selisih 2,28 Volt DC. Hal ini dikarenakan adanya IC regulator 7875 agar mempertahankan tegangan input mikrokontroller tidak lebih dari 5 Volt DC.

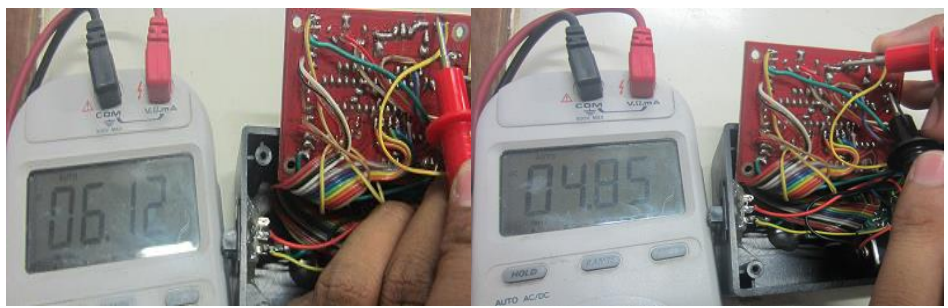

Gambar 10. Hasil pengukuran mikrokontroller 


\section{Pengujian Seven Segment}

Untuk menampilkan hasil pengukuran sensor accelerometer penulis menggunakan seven segment dengan ukuran 2 X 4 . Penulis menggunakan seven segment dengan ukuran tersebut karena tampilannya lebih mudah dilihat dari sisi depan maupun sisi samping. Seven segment tersebut diletakkan pada sisi miring clinometer digital, yang tergabung menjadi satu dengan komponen lainnya.

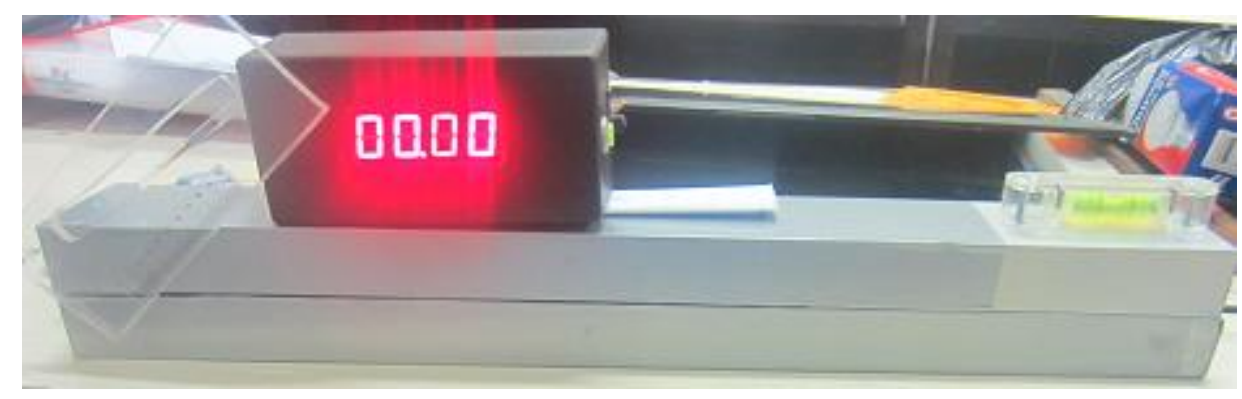

Gambar 11. Tampilan Seven Segment

\section{Perangkat Lunak Sensor Accelerometer}

Keluaran sensor accelerometer merupakan data asli yang berupa data alduino. Data arduino merupakan data digital yang menunjukkan posisi sensor tersebut. Pada saat $0^{\circ}$ sensor accelerometer mengeluarkan data 89 dan pada saat $90^{\circ}$ sensor tersebut mengeluarkan data 1459. Selisih antara data tersebut adalah 1370.

Selisih data tersebut digunakan untuk mencari faktor pembagi untuk merubah data asli alduino menjadi data berupa sudut. Dari hasil tersebut selanjutnya data dikirim menuju mikrokontroller untuk diolah.

\section{KESIMPULAN}

Dari pengujian yang dilakukan clinometer digital sebagai seting sudut PAPI maka dapat diambil kesimpulan sebagai berikut :

1. Clinometer Digital ini mudah di operasikan, memiliki tampilan yang sederhana, ekonomis dan efisien.

2. Tingkat kesalahan pembacaan clinometer digital ini masih dalam toleransi maksimal yaitu 0,07 derajat.

\section{Daftar Pustaka}

[1] Direktorat Jenderal Perhubungan Udara. (2013). KP. 2 Tahun 2013 tentang Kriteria Penempatan Peralatan dan Utilitas Bandar Udara. Jakarta : Direktorat Jenderal Perhubungan Udara.

[2] Direktorat Jenderal Perhubungan Udara. (2004). Manual Of Standart Aerodrome. Jakarta : Direktorat Jenderal Perhubungan Udara.

[3] Humaidi, Abdul Haris. (2009). Fisika SMA/MA Kelas XI. Jakarta : Pusat Perbukuan, Departemen Pendidikan Nasional. 
[4] Kustori, K., \& Suhanto, S. (2018). Rancangan Alat Re-setting Precision Approach Path Indicator (PAPI) Menggunakan Motor DC Dengan Sistem Computerize. Jurnal Penelitian, 3(1), 27-31.

[5] Marsigit. (2007). Matematika SMP Kelas VIII. Jakarta : Yudistira. 